\title{
Analisa Ketelitian Geometric Citra Satelit Pleiades 1A Metode Orthorektifikasi Rigorious sebagai Dasar Pembuatan Peta Desa (Studi Kasus: Kelurahan Kenjeran)
}

\author{
Hanif Khoirul Latif, Bangun Muljo Sukojo \\ Jurusan Teknik Geomatika, Fakultas Teknik Sipil dan Perencanaan, Institut Teknologi Sepuluh \\ Nopember (ITS) \\ J1. Arief Rahman Hakim, Surabaya 60111 Indonesia \\ e-mail: bangunms@gmail.com
}

\begin{abstract}
Abstrak-Peta desa merupakan peta tematik bersifat dasar yang berisi unsur dan informasi batas wilayah, infrastruktur transportasi, toponim, perairan, sarana prasarana, penutup lahan dan penggunaan lahan yang disajikan dalam peta citra, peta sarana dan prasarana, serta peta penutup lahan dan penggunaan lahan. Peta desa dapat disajikan dengan ukuran 1:2500, 1:5000 atau 1:10000. Kelurahan Kenjeran memiliki ukuran 55" pada lintang dan 46" pada bujur. Sehingga untuk membuat peta desa Kenjeran memerlukan skala 1:5000. Peta dengan skala 1:5000 dapat dibuat dengan citra dengan resolusi tinggi dengan nilai ketelitian peta desa yang harus dipenuhi. Ketentuan nilai ketelitian peta tersebut diatur oleh Badan informasi Geospasial (BIG). Data citra satelit yang digunakan dalam penelitian ini adalah citra satelit Pleiades 1A. Metode koreksi geometric yang digunakan dalam penelitian ini adalah orthorektifikasi metode rigorious. Digunakan 8 Ground Control Point (GCP) yang didapatkan dari pengukuran GPS geodetik dengan metode statik dengan lama pengamatan 60 menit tiap titik. Digunakan 12 Independence Check Point (ICP). Hasil dari penelitian ini adalah bahwa citra satelit Pleiades 1A Menurut Perka BIG No. 3 Tahun 2016 Tentang Spesifikasi Teknis Penyajian Peta Desa layak untuk digunakan dalam pembuatan peta citra Desa/Kelurahan Kenjeran dengan skala 1:5000 dengan kelas ketelitian 3. Hal tersebut dikarenakan Nilai RMSe citra satelit Pleiades 1A adalah 0,69. Analisis ketelitian geometric yang dilakukan mendapatkan nilai RMSe sebesar 1,479 m sehingga nilai CE90 yang didapatkan sebesar $2,244 \mathrm{~m}$.
\end{abstract}

Kata Kunci-Koreksi Geoetrik, Orthorektifikasi, Peta Desa, Pleiades 1A, RMSe

\section{PENDAHULUAN}

$\mathrm{D}$ ESA adalah desa dan desa adat atau yang disebut dengan nama lain adalah kesatuan masyarakat hukum yang memiliki batas wilayah yang berwenang untuk mengatur dan mengurus urusan pemerintahan, kepentingan masyarakat setempat berdasarkan prakarsa masyarakat, hak asal usul, dan/atau hak tradisional yang diakui dan dihormati dalam sistem pemerintahan Negara Kesatuan Republik Indonesia [5]. Dalam mengatur dan mengurus kepentingan masyarakatnya sendiri sebuah desa maupun kelurahan harus mengetahui semua potensi yang dimilikinya. Sarana sederhana dan mudah dimengerti untuk melakukan hal tersebut adalah peta. Peta adalah ekspresi visual dari porsi-porsi yang ada di muka bumi
[3]. Peta yang dibutuhkan untuk menggambarkan potensi desa atau kelurahan haruslah peta dengan skala besar antara 1:2500 sampai 1:10000. Pemilihan skala peta desa mempertimbangkan penyajian seluruh wilayah desa dalam satu muka peta [2]. Pada kertas A0 Peta dengan skala 1:2500 mencakup desa dengan ukuran 54" lintang dan 54" bujur. Peta dengan skala 1:5000 mencakup desa dengan ukuran 1' 54" lintang dan 1'54" bujur. Peta dengan skala 1:10000 mencakup desa dengan skala 3' 48' lintang dan 3' 48' bujur [2]. Peta dengan skala besar tersebut akan memberikan gambaran detil dari potensi desa atau kelurahan yang dipetakan sehingga memudahkan dalam interpretasi.

Dibutuhkan klasifikasi tertentu agar sebuah citra dapat digunakan sebagai dasar dalam pembuatan peta desa/keluahan. Pembuat spesifikasi kelayakan sebuah citra ketika digunakan sebagai dasar pembuatan peta desa/kelurahan adalah Badan Informasi Geospasial dalam Perka BIG No. 3 Tahun 2016 Tentang Spesifikasi Penyajian Peta Desa. Penelitian ini akan membahas mengenai analisa ketelitian geometric dari citra satelit sehingga bisa disimpulkan bahwa citra tersebut layak atau tidak layak ketika digunakan sebagai dasar dalam pembuatan peta desa/kelurahan. Citra satelit yang digunakan dalam penelitiain ini adalah citra satelit Pleiades 1A. Satelit optis Pleiades dikembangkan dan diluncurkan oleh AIRBUS Defense and Space, Prancis. Diluncurkan melalui roket Russia Soyuz STA di Pusat Peluncuran Guiana, Kourou. Satelit ini dibedakan berdasarkan 2 tipe sensor yaitu Pleiades-1A dan Pleiades 1B [4].

\section{METODOLOGI PENELITIAN}

\section{A. Lokasi Penelitian}

Penelitian ini dilakukan di Kelurahan Kenjeran yang terletak pada $7^{\circ} 13^{\prime} 37^{\prime}$ ' LS - $7^{\circ} 14^{\circ} 32^{\circ} \mathrm{LS}$ dan $112^{\circ} 47^{\prime} 2^{\prime \prime}$ BT $-112^{\circ}$ 47' 48', BT. Sedangkan secara administratif termasuk dalam wilayah Kecamataan Bulak. 


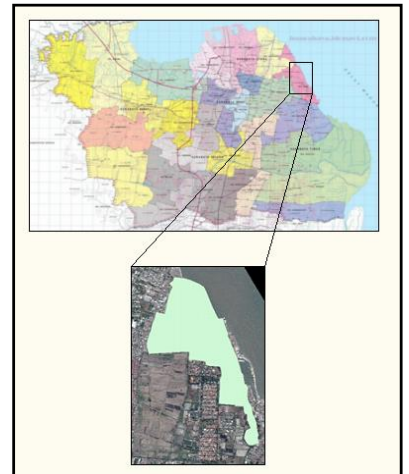

Gambar 1. Lokasi Penelitian

\section{B. Data dan Peralatan}

a. Data

Data yang digunakan dalam penelitian tugas akhir ini adalah:

1. Citra Satelit Pleiades 1A akuisisi data tanggal 28 Agustus 2015 dengan level proses L0 atau primer

2. Independence Check Point (ICP) 12 titik

3. Ground Control Point (GCP) 8 titik

4. Digital Elevation Model Alos Palsar dengan resolusi spasial 12,5 m akuisisi tanggal 13 Agustus 2015

b. Peralatan

Peralatan yang digunakan dalam penelitian tugas akhir ini adalah:

1. Perangkat Keras:

i. Receiver GNSS Geodetik

ii. Laptop

iii. Receiver GPS Handheld

iv. Roll meter

v. Kompas

vi. Kamera

2. Perangkat Lunak:

i. Perangkat lunak pengolah citra

ii. ArcGIS 10.1

iii. Topcon Tools

iv. Windows 7

v. Microsoft Office 2010

\section{Tahap Pengolahan Data}

Tahapan pertama yang dilakukan adalah melakukan fusi citra. Proses fusi citra dilakukan dengan menggabungkan band multispektral dan pankromatik dari citra satelit Pleiades 1A. Tahapan selanjutnya adalah pemilihan lokasi untuk peletakan Ground Control Point (GCP). GCP diletakkan pada kenampakan permukaan bumi yang mudah dikenali pada citra yang digunakan dengan kemungkinan perubahan yang relatif lambat atau bisa dikatakan sulit untuk berubah. Kenampakan alam yang dipilih adalah pada tepi perempatan jalan, tepi sungai dan titik jatuh air pada bangunan. Penentuan titik $G C P$ tersebar merata diseluruh wilayah penelitian pada citra satelit yang digunakan. Tersebar meratanya GCP tersebut untuk memastikan bahwa proses rektifikasi yang dilakukan berhasil dengan maksimal. Dalam penelitian ini penulis menggunakan delapan titik GCP.

Setelah ditentukannya delapan titik GCP langkah selanjutnya adalah membetuk jaring-jaring dengan cara menghubungkan titik-titik GCP tersebut. Setelah jaring-jaring tersebut terbentuk dilakukan penghitungan Strength of Figure (SoF). Penghitungan SoF harus mendapatkan nilai <1 [1].

Setelah nilai SoF didapatkan berikutnya adalah melakukan pengukuran GCP. Pengukuran GCP dilakukan dengan menggunakan empat receiver GNSS geodetik dengan metode statik.

Hasil dari pengukuran GCP digunakan untuk melakukan koreksi geometric pada peta. Koreksi geometric tersebut dilakukan dengan orthorektifikasi menggunakan metode Rigorious disertai dengan DEM Alos Palsar. Di dalam koreksi geometric suatu citra, RMSe digunakan untuk menilai derajat kesalahan dengan membandingkan koordinat GCP hasil pengukuran lapangan dengan koordinat citra satelit. Ketelitian transformasi ditentukan oleh harga RMSe. Semakin kecil harga RMSe-nya maka semakin teliti penentuan GCP di citra.

Setelah melakukan koreksi geometric dilakukan analisa terhadap ketelitian geometric yang didapatkan. Analisa tersebut dilakukan dengan menggunakan ICP. Nilai RMSe dari hasil uji ketelitian geometric digunakan untuk mengetahui kelayakan citra tersebut melalui analisa ketelitian horizontal peta desa yang dikeluarkan oleh Badan Informasi Geospasial.

\section{HASIL DAN PEMBAHASAN}

\section{A. Penentuan Lokasi GCP}

Lokasi yang dipilih oleh peneliti adalah lokasi yang dapat dengan mudah diinterpretasikan dalam peta. Seperti yang terlihat pada gambar 2, GCP terletak pada titik jatuh air pada bangunan kantor Kecamatan Bulak. Begitu pula yang dilakukan oleh penulis dalam meletakkan 7 titik GCP lainnya.

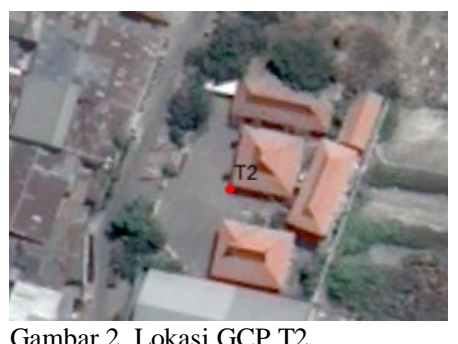

\section{B. Kekuatan Desain Jaring}

Kekuatan desain jaring dihitung dengan menggunakan metode kuadrat terkecil (least square) dengan komponen rumus sebagai berikut:

- Jumlah baseline $(\mathrm{N})$

- Jumlah titik (S)

- S'

- N'

- $C=C_{a}+C_{s}=\left(N^{\prime}-S^{\prime}+1\right)+(N-2 S+3)$

- $D=2 x\left(N^{\prime}-1\right)+\left(N-N^{\prime}\right)$

- $\left[\sum\left(\delta_{A}^{2}+\delta_{A} \cdot \delta_{B}+\delta_{B}^{2}\right)\right]$

- $R=\frac{(D-C)}{C}\left[\sum\left(\delta_{A}^{2}+\delta_{A} \cdot \delta_{B}+\delta_{B}^{2}\right)\right]$

Kekuatan desain jaring yang didapatkan sebesar 0,100584 . 


\section{Koordinat GCP}

Daftar koordinat GCP (X,Y) yang didapatkan dari pengukuran dilapangan dan telah terikat ke datum SRGI 2013 tersaji dalam tabel 1. Daftar koordinat $G C P$ tersebut digunakan untuk melakukan koreksi geometric citra satelit yang digunakan.

Tabel 1.

Koordinat GCP

\begin{tabular}{cccc}
\hline \hline No. & $\begin{array}{c}\text { Nama } \\
\text { Titik }\end{array}$ & $\begin{array}{c}\text { Titik Kontrol Terikat SRGI 2013 } \\
\mathbf{X}(\mathbf{m})\end{array}$ & $\mathbf{Y}(\mathbf{m})$ \\
\hline 1. & T1 & 697391,207 & 9200900,523 \\
2. & T2 & 697133,585 & 9200257,729 \\
3. & T3 & 697967,693 & 9200297,157 \\
4. & T4 & 697750,935 & 9199630,680 \\
5. & T5 & 698214,718 & 9199773,717 \\
6. & T6 & 697987,449 & 9199229,007 \\
7. & T7 & 698523,506 & 9199272,642 \\
8. & T8 & 698400,793 & 9198526,452 \\
\hline \hline
\end{tabular}

D. Perhitungan Root Mean Square Error (RMSe)

RMSe koreksi geometric per titik dan total RMSe tersaji pada tabel 2.

Tabel 2.

RMSe Citra Satelit Worldview-2

\begin{tabular}{lcccc}
\hline No. & $\begin{array}{c}\text { Nama } \\
\text { Titik }\end{array}$ & $\begin{array}{c}\text { Residu } \\
\text { (piksel) }\end{array}$ & $\begin{array}{c}\text { RMSe } \\
\text { Residu X } \\
\text { (piksel) }\end{array}$ & $\begin{array}{c}\text { Residu Y } \\
\text { (piksel) }\end{array}$ \\
\hline 1. & T1 & 0,40 & $-0,08$ & $-0,39$ \\
2. & T2 & 0,74 & $-0,70$ & $-0,24$ \\
3. & T3 & 0,84 & $-0,63$ & $-0,55$ \\
4. & T4 & 0,69 & $-0,61$ & $-0,31$ \\
5. & T5 & 0,66 & $-0,64$ & $-0,16$ \\
6. & T6 & 0,55 & $-0,28$ & $-0,47$ \\
7. & T7 & 0,80 & $-0,75$ & $-0,28$ \\
8. & T8 & 0,53 & $-0,29$ & $-0,45$ \\
Total RMSE & & 0,67 & \\
\hline \hline
\end{tabular}

Berdasarkan hasil perhitungan RMSe pada tabel 2 diketahui bahwa nilai RMSe koreksi geometric yang didapatkan dari orthorektifikasi menggunakan metode Rigorious memenuhi toleransi yang diberikan yakni 1,5 dikali bilangan resolusi spasial dari citra Pleiades 1A yang sebesar 0,5 piksel. Nilai toleransi tersebut sebesar 0,75 piksel.

\section{E. Analisa Ketelitian Geometric}

Analisa Ketelitian geometric didapatkan dengan mendapatkan RMSe dari citra satelit yang digunakan. RSME didapatkan dari residu dari selisih koordinat hasil pengukuran ICP dan titik koordinat dari lokasi ICP tersebut pada citra satelit. Persebaran ICP tersaji dalam gambar 3. Daftar koordinat ICP yang telah diikatkan ke datum SRGI 2013 tersaji dalam tabel 3 .

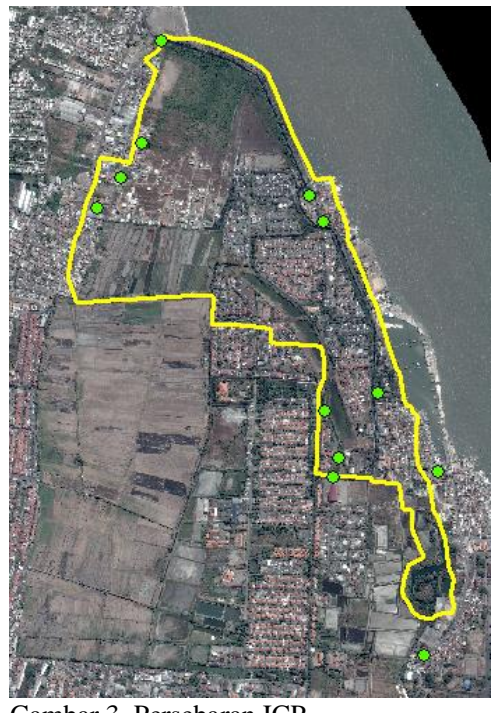

Gambar 3. Persebaran ICP

Tabel 3.

Koordinat ICP

\begin{tabular}{ccc}
\hline \multicolumn{3}{c}{ Koordinat ICP } \\
\multirow{2}{*}{ Titik } & $\mathbf{X}(\mathbf{m})$ & $\mathbf{Y}(\mathbf{m})$ \\
\hline 1 & 698388,706 & 9198532,239 \\
2 & 697953,367 & 9200294,118 \\
3 & 697395,418 & 9200883,123 \\
4 & 697321,393 & 9200491,446 \\
5 & 697239,263 & 9200359,756 \\
6 & 697150,028 & 9200243,373 \\
7 & 698006,255 & 9200189,779 \\
8 & 698216,103 & 9199534,547 \\
9 & 698042,735 & 9199212,545 \\
10 & 698063,540 & 9199287,301 \\
11 & 698010,777 & 9199467,796 \\
12 & 698442,039 & 9199236,256 \\
\hline \hline
\end{tabular}

Tabel 4.

Koordinat ICP pada citra Pleiades 1A

\begin{tabular}{crc}
\hline \multirow{2}{*}{ Titik } & $\mathbf{X}(\mathbf{m})$ & Koordinat ICP \\
& $\mathbf{Y}(\mathbf{m})$ \\
\hline 1 & 698387,576 & 9198531,533 \\
2 & 697952,818 & 9200295,637 \\
3 & 697395,550 & 9200885,092 \\
4 & 697322,468 & 9200492,064 \\
5 & 697237,644 & 9200360,619 \\
6 & 697149,852 & 9200244,335 \\
7 & 698005,184 & 9200190,245 \\
8 & 698216,520 & 9199533,387 \\
9 & 698043,068 & 9199212,074 \\
10 & 698064,364 & 9199286,729 \\
11 & 698008,300 & 9199467,041 \\
12 & 698443,090 & 9199236,509 \\
\hline \hline
\end{tabular}

Letak hasil pengukuran ICP pada citra satelit Worldview-2 tersaji dalam tabel 4. Residu yang didapatkan dari selisih koordinat dari citra satelit Pleiades 1A kemudian digunakan untuk mendapatkan RMSe koordinat citra. RMSe koordinat citra satelit Pleiades 1A tersaji dalam tabel 5.

\begin{tabular}{ccc}
\multicolumn{3}{c}{$\begin{array}{c}\text { Tabel 5. } \\
\text { Residu }\end{array}$} \\
\hline \hline Titik & Residu X $(\mathbf{m})$ & Residu Y (m) \\
\hline 1 & $-1,130$ & $-0,706$ \\
2 & $-0,548$ & 1,519 \\
3 & 0,132 & 1,969 \\
4 & 1,075 & 0,618 \\
\hline
\end{tabular}




\begin{tabular}{ccc}
\hline 5 & $-1,619$ & 0,863 \\
6 & $-0,176$ & 0,962 \\
7 & $-1,071$ & 0,466 \\
8 & 0,418 & $-1,161$ \\
9 & 0,333 & $-0,471$ \\
10 & 0,824 & $-0,572$ \\
11 & $-2,477$ & $-0,756$ \\
12 & 1,052 & 0,253 \\
& RMSe & 1,479 \\
\hline \hline
\end{tabular}

\section{F. Nilai Ketelitian Peta Desa}

Ketelitian peta adalah nilai yang menggambarkan tingkat kesesuaian antara posisi dan atribut sebuah objek di peta dengan posisi dan atribut sebenarnya. [2]. Badan Informasi Geospasial telah menetapkan tingkat standar ketelitian horizontal peta desa seperti yang tertera pada tabel 6 .

Tabel 4.

Standar Ketelitian Horizontal Peta Desa

\begin{tabular}{ccccc}
\hline \hline \multirow{2}{*}{ No. } & \multirow{2}{*}{ Skala Peta } & \multicolumn{3}{c}{ Ketelitian horizontal (m) } \\
& & Kelas 1 & Kelas 2 & Kelas 3 \\
\hline 1. & $1: 10000$ & 2 & 3 & 5 \\
2. & $1: 5000$ & 1 & 1,5 & 2,5 \\
3. & $1: 2500$ & 0,5 & 0,75 & 1,25 \\
\hline \hline
\end{tabular}

Nilai ketelitian peta desa adalah nilai (Circular Error) CE90 untuk ketelitian horizontal, yang berarti bahwa kesalahan posisi peta desa tidak melebihi nilai ketelitian tersebut dengan tingkat kepercayaan 90\%. Nilai CE90 diperoleh dengan rumus sebagai berikut:

CE90 = 1,5175 $\times$ RMSe

Perhitungan nilai ketelitian peta menghasilkan nilai CE90 sebesar 2,244.

\section{KESIMPULAN DAN SARAN}

Kesimpulan dari penelitian ini adalah sebagai berikut.

1. RMSe koreksi geometric citra satelit Pleiades 1A dengan 8 GCP menggunakan metode orthorektifikasi Rigorious sebesar 0,69 piksel memenuhi toleransi dari nilai RMSe yang diizinkan yakni 0,75 piksel.

2. RMSe analisa ketelitian geometric citra satelit Pleiades 1A dengan 12 ICP menggunakan metode orthorektifikasi Rigorious sebesar $1,479 \mathrm{~m}$.

3. Nilai CE90 yang didapatkan dari citra satelit Pleiades 1A hasil orthorektifikasi metode Rigorious sebesar 2,244 m. Menurut Perka BIG No. 3 Tahun 2016 Tentang Spesifikasi Teknis Penyajian Peta Desa, citra satelit Pleiades hasil ortho rektifikasi baik metode RPC maupun Rigorious layak untuk digunakan dalam pembuatan peta desa Kelurahan Kenjeran dengan skala 1:5000 pada kelas ketelitian 3 dimana ketelitian maksimal yang diperbolehkan adalah $2,5 \mathrm{~m}$.

Saran yang digunakan untuk rekomendasi penelitian selanjutnya adalah:

1. Membuat sama waktu pengukuran ICP dengan waktu pengukuran GCP sehingga ketika koordinat ICP digunakan untuk melakukan analisa ketelitian geometric mendapatkan hasil yang lebih maksimal.
2. Menggunakan DEM yang memiliki selisih resolusi spasial tidak begitu jauh berbeda dari resolusi spasial citra satelit yang digunakan.

\section{DAFTAR PUSTAKA}

[1] Abidin, H.Z. 2000. Penentuan Posisi dengan GPS dan Aplikasinya. Pradnya Paramita. Jakarta.

[2] Badan Informasi Geospasial. 2016. Spesifikasi Teknis Penyajian Peta Desa. Sekretariat BIG. Cibinong.

[3] Ghilani, Charles D. Paul. Pau R. Wolf. 2012. Elementary Surveying: An Introduction to Geomatics. Pearson. New Jersey.

[4] Pusfatekgan LAPAN. 2014. Data Citra Satelit <URL: http://pusfatekgan.lapan.go.id/testing/>. Dikunjungi pada tanggal 14 Desember 2015, pukul 20.00.

[5] Republik Indonesia. 2014. Undang-Undang No. 6 Tahun 2014 tentang Desa. Sekretariat Negara. Jakarta. 